\title{
Showroom Mobil Dengan Pendekatan Arsitektur Hightech Di SURAKARTA
}

\author{
Riyan Pandu Wijayanto, Suparno, Hari Yuliarso \\ Program Studi Arsitektur \\ Fakultas Teknik \\ Universitas Sebelas Maret Surakarta \\ Email : malangjatim496@gmail.com
}

\begin{abstract}
Car Showroom Design of Architectural Approach Hightech in Surakarta triggered by the growth of four-wheeled vehicles is increasing from year to year and the needs of the community will maintenace or care of the car is also increasing. This showroom is made as facilities for various service activities container full four-wheeled vehicles in one building. Hightech architecture is used as a showroom for design approach in line with the image of a car showroom representing a technology, sophisticated, flexible, functional. The method used is a method of designing architecture with Hightech Architecture approach. Architecture Hightech made for functional reasons, but for the future, this architecture could be an attempt to expose and play with building elements both inside and outside elements. By using this approach showroom building is designed with aesthetic appearance and good, as it represents the function of the container activities of the facility four-wheel vehicles in it.
\end{abstract}

Keywords: Architecture, Architecture Hightech, Car Showroom, Car Facilities

\section{PENDAHULUAN}

Masyarakat umum menyebut showroom hanya tempat untuk memajang kendaraan, karena secara global dan sudah menjadi kebiasaan berasumsi bahwa tempat untuk memajang bernama showroom. Di mana showroom atau ruang pamer mobil merk umum yang sudah mendunia dan berada dalam satu negara terdiri dari beberapa cabang dalam satu kota dan hanya ada satu pusat dalam satu negara, serta ruang pamer mobil bekas atau yang sering disebut Mobkas, dengan berbagai merk mobil serta tidak memberikan fasilitas lengkap, maka masyarakat tetap menyebutnya showroom mobil bekas. Kata-kata showroom pun menjadi sama pengertiannya yaitu tempat untuk memajang mobil. Padahal kata showroom tidak demikian artinya, showroom adalah wilayah atau tempat yang menyediakan jasa jual beli mobil dengan fasilitas lengkap seperti servis (bengkel), spare part dan fasilitas pendukung lainnya (Gilbert Mc Devinn,2009). Selain itu showroom juga dapat diartikan sebagai tempat display untuk furniture ataupun barang yang memang untuk dipamerkan. Tujuan showroom dibuat untuk memberikan fasilitas akan kebutuhan, di mana kebutuhan kendaraan saat ini sangat kompleks. Badan Pusat Statistik (BPS) mencatat adanya kenaikan pertumbuhan industri manufaktur besar dan sedang pada triwulan III-2014 sebesar $5,6 \%$ jika dibandingkan dengan periode yang sama di tahun 2013. Salah satu yang menopang kenaikan ini adalah pertumbuhan industri kendaraan bermotor sebesar 29,7\%. Pesatnya pertumbuhan kendaraan bermotor, harus di dukung oleh pemerintah melalui penyediaan infrastruktur yang memadai, terutama pada kendaraan bermotor roda empat (mobil). Showroom mobil yang di bangun oleh APM mempunyai peran penting sebagai ujung tombak distributor dalam penjualan dan pelayanan purna jual, sehingga setiap Showroom mobil akan berusaha untuk memberikan pelayanan yang memuaskan dari saat pembelian mobil 
sampai dengan pelayanan purna jualnya. Seiring dengan fakta di atas, kebutuhan masyarakat akan maintenace atau perawatan terhadap mobil juga lebih kompleks dan semakin bertambah. Showroom ini dibuat sebagai fasilitas untuk berbagai wadah kegiatan pelayanan kendaraan roda empat yang lengkap dalam satu bangunan. Arsitektur Hightech digunakan sebagai pendekatan desain showroom karena sejalan dengan citra showroom mobil yang mewakili sebuah teknologi, muthakir, canggih, fleksible, fungsional. Arsitektur Hightech dibuat karena alasan fungsional, tetapi untuk ke depannya arsitektur ini bisa menjadi upaya untuk mengekspos dan bermain dengan elemenelemen bangunan baik elemen dalam maupun luar. Dengan menggunakan pendekatan ini bangunan showroom dirancang dengan tampilan yang estetis dan baik sebagaimana mewakili fungsi kegiatan di dalamnya.

2. METODE

\subsection{Macam dan Teknik Pengumpulan Data}

1. Data Topografi: didapat melalui observasi dan dokumentasi rupa muka tanah, selain itu data juga didapat melalui data instansional pemerintah kota serta melalui situs dan artikel terkait.

2. Data Kewilayahan: didapat melalui data instansional pemkot serta melalui situs dan artikel terkait.

3. Kondisi showroom: didapat dengan observasi dan dokumentasi beberapa showroom di Surakata serta wawancara dengan sumber yang terpercaya. Data lain didapat dari artikel terkait.

4. Arsitektur Hightech: data didapat dari mata kuliah tentang struktur serta beberapa buku referensi.

\subsection{Metode Analisis Data}

Analisis perencanaan (building concept) mengidentifikasi masalah yang ada berdasarkan konsep showroom mobil yang diselesaikan dengan aspek arsitektur hightech namun tetap memperhatikan unsur fungsional bangunan showroom tersebut.

Analisis perancangan (building criteria) dilakukan dengan mengolah data yang telah terkumpul dan dikelompokkan berdasarkan programing fungsional, performasi, dan arsitektural.

1. Pemrograman fungsional bertujuan untuk mengidentifikasi penggunaan showroom mobil, di antaranya pelaku kegiatan, jenis kegiatan, pola kegiatan, sifat kegiatan, sifat kepemilikan lembaga usaha.

2. Pemrograman performasi menerjemahkan secara sistematik kebutuhan para pengguna showroom berserta fasilitasnya ke dalam persyaratan pemilihan tapak, persyaratan kebutuhan ruang, persyaratan besaran ruang dan program ruang, serta penggunaan selubung bangunan untuk mendapatkan bangunan yang direncanakan.

3. Analisis arsitektural merupakan tahap penggabungan dari hasil identifikasi kedua analisa sebelumnya (fungsional dan performasi). Dalam proses ini akan menganalisa masalah massa, ruang, tampilan, pengolahan tapak, utilititas, dan struktur bangunan.

\section{ANALISIS}

\subsection{Analisis Peruangan}

Tabel 1.Kebutuhan Ruang

\begin{tabular}{|l|l|l|}
\hline PELAKU & KEGIATAN & PERUANGAN \\
\hline Pengunjung & $\begin{array}{l}\text { Melihat mobil } \\
\text { baru dan bekas }\end{array}$ & Showroom \\
\cline { 2 - 3 } & Service mobil & Service area \\
\cline { 2 - 3 } & $\begin{array}{l}\text { membeli } \\
\text { sparepart }\end{array}$ & Sparepart area \\
\cline { 2 - 3 } & $\begin{array}{l}\text { Membeli } \\
\text { aksesoris }\end{array}$ & Aksesoris \\
\hline Pengelola & $\begin{array}{l}\text { Mengelola } \\
\text { fasilitas } \\
\text { showroom }\end{array}$ & Area pengelola \\
\hline
\end{tabular}

Pada Tabel 1. terlihat kebutuhan peruangan yang dibutuhkan dalam pemenuhan wadah kegiatan utama pada showroom. 
Riyan Pandu Wijayanto, Suparno, Hari Yuliarso, Showroom Mobil dengan Pendekatan Arsitektur ...

\subsection{Analisis Lokasi}

Selain menentukan lokasi yang strategis, memilih tapak dengan kondisi yang mendukung keberadaan showroom ini sangat menentukan prospek bangunan tersebut.

a. Tujuan

Mendapatkan lokasi yang sesuai dengan showroom mobil .

b. Dasar pertimbangan:

Posisi tapak strategis untuk ekspose tampilan fisik bangunan yang merupakan bangunan komersial, luasan tapak dapat menampung seluruh kebutuhan ruang yang direncanakan.

\subsection{Analisis Pencapaian}

Pencapaian ke dalam bangunan harus mudah diakses, mudah dilihat dan memiliki sirkulasi yang aman akan merangsang orang untuk masuk dalam area bangunan.

1. Tujuan: menentukan main entrane, menentukan service entrance

2. Dasar Pertimbangan: kemudahan akses, sirkulasi tapak yang aksesibel, arus kendaraan dan potensi jalan, tingkat keamanan.

3. Proses analisis

Main Entrance (ME)

Mudah dijangkau dan terlihat dengan jelas. Menghadap langsung ke arah jalan untuk kemudahan sirkulasi kendaraan masuk dan ke luar tapak.

Side Entrance (SE)

Tidak mengganggu keberadaan ME. Membantu sirkulasi pengunjung.

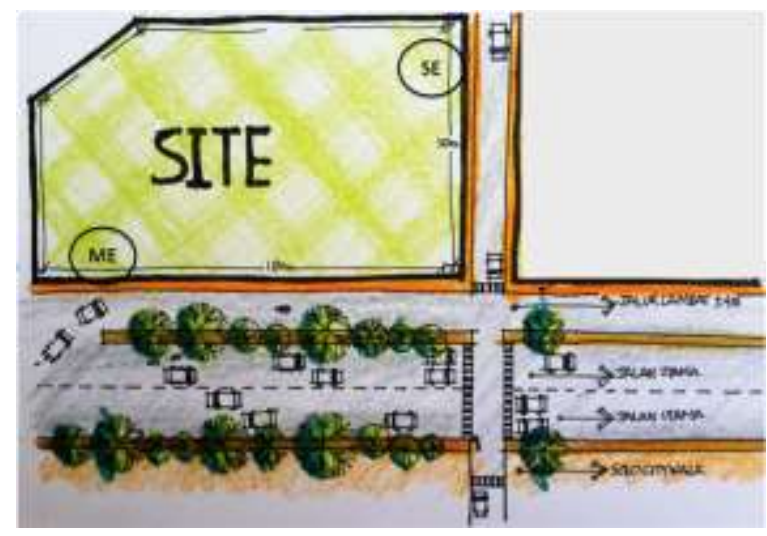

Gambar 1. Pola Pencapaian

\subsection{Analisis Penzoningan}

Penzoningan berdasarkan sifat kegiatan dan keadaan dalam tapak dilakukan sebagai acuan dalam penataan peruangan, namun tetap memperhatikan modul-modul struktur yang telah diterapkan.

1. Tujuan: Menentukan pengelompokan (zoning) berdasarkan sifat kegiatan dan keadaan pada tapak.

2. Dasar pertimbangan: analisis peruangan, analisis pengolahan tapak, analisis sirkulasi.

3. Proses analisis: persyaratan ruang, berdasarkan kelompok kegiatan dan analisis pengolahan tapak.

Tabel 2. Persyaratan Ruang

\begin{tabular}{|l|l|l|l|}
\hline ZONA & $\begin{array}{c}\text { KEL. } \\
\text { RUANG }\end{array}$ & $\begin{array}{r}\text { PERSY } \\
\text { ARAT } \\
\text { AN }\end{array}$ & $\begin{array}{l}\text { IMPLIKASI } \\
\text { PERUANGAN }\end{array}$ \\
\hline Publik & Pengunjung & $\begin{array}{l}\text { Pencapaia } \\
\text { n mudah } \\
\text { View } \\
\text { from/to } \\
\text { site, } \\
\text { pencahaya } \\
\text { an alami }\end{array}$ & $\begin{array}{l}\text { Peruangan } \\
\text { dimakasimalkan } \\
\text { agar mudah } \\
\text { dijangkau dari } \\
\text { segala sisi, } \\
\text { menghidari } \\
\text { ruang dalam } \\
\text { ruang }\end{array}$ \\
\hline $\begin{array}{l}\text { Semi } \\
\text { publik }\end{array}$ & Pengelola & $\begin{array}{l}\text { Pencapaia } \\
\text { n telihat } \\
\text { Noise }\end{array}$ & $\begin{array}{l}\text { Area } \text { indoor } \\
\text { pengelola tidak } \\
\text { menggangu } \\
\text { sirkulasi } \\
\text { pengunjung, } \\
\text { ruangan kedap } \\
\text { suara }\end{array}$ \\
\hline
\end{tabular}

\subsection{Analisis Bentuk dan Tampilan Bangunan}

\subsubsection{Analisis Bentuk Bangunan}

Citra pada tampilan bangunan Menyesuaikan dengan karakteristik bangunan showroom mobil dengan Pendekatan Arsitektur Hightech yang merupakan penggunaan teknologi tinggi pada bangunan serta mencitrakan karakter teknologi tinggi pada bangunan.

\subsubsection{Penampilan Bentuk Dasar Bangunan}

Bentuk massa di dominasi oleh bentuk dasar yaitu segiempat, segitiga, lingkaran 
dengan pertimbangan aspek fungsional dan efisiensi ruang sebagai bangunan komersial. Bentuk dasar massa yang lain menggunakan filosofis dari komponen kendaraan dan gabungan filosifis dari karakter teknologi tinggi dan streamline seperti pada Gambar 2.

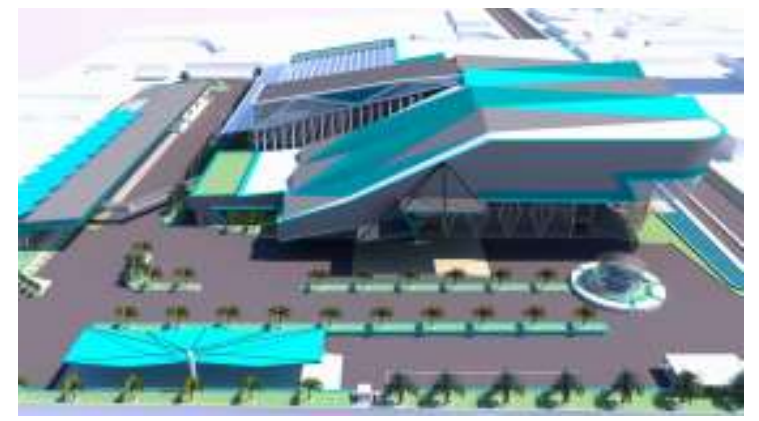

Gambar 2. Massa bangunan yang mengambil filosofis bentuk kendaraan yang streamline.

\subsection{Analisis Penampilan dan Karakteristik Bangunan}

1. Tujuan: mendapatkan massa yang menarik dan mencerminkan hightech.

2. Dasar pertimbangan: prinsip dasar showroom, penggunaan struktur yang tepat, salah satu bagian yang dapat dijadikan ekspose bangunan.

3. Proses analisis

Mewakili sebuah bangunan showroom sebagai bangunan yang di peruntukan sebagai bangunan komersial yang mewakili citra teknologi tinggi sebuah kendaraan roda empat yang memiliki beberapa aspek ,di antara lain : teknologi muthakir, canggih, fleksible, fungsional. Di mana showroom mobil ini mewakili karakter yang diwadahi pada bangunan yaitu kendaraan roda empat. Menunjang fungsi wadah dan kegiatan yang berlangsung di dalam bangunan

Bentuk massa didominasi oleh bentuk dasar yaitu segiempat, segitiga, lingkaran dengan pertimbangan aspek fungsional dan efisiensi ruang sebagai bangunan komersial. Bentuk dasar massa yang lain menggunakan filosofis dari komponen kendaraan dan gabungan filosifis dari karakter teknologi tinggi dan kendaraan.

\subsection{Analisa Struktur}

1. Tujuan: mendapatkan sistem struktur yang sesuai dengan pembebanan.

2. Dasar Pertimbangan: beban yang harus didukung, kondisi tanah, bentuk dan dimensi bentang bangunan, karakter bangunan, pengaruh terhadap lingkungan sekitar.

3. Analisa

a. Substructure

Tabel.1 Analisa substructure

\begin{tabular}{|l|c|c|c|}
\hline \multicolumn{1}{|c|}{ Kriteria } & Sumuran & $\begin{array}{c}\text { Tiang } \\
\text { pancang }\end{array}$ & $\begin{array}{c}\text { Foot } \\
\text { plate }\end{array}$ \\
\hline $\begin{array}{l}\text { Daya dukung } \\
\text { thd bangunan } \\
\text { berlantai } \\
\text { banyak }\end{array}$ & Baik & Cukup & Cukup \\
\hline $\begin{array}{l}\text { Kemudahan } \\
\text { dan } \\
\text { kecepatan } \\
\text { mengerjakan }\end{array}$ & Baik & Cukup & Cukup \\
\hline $\begin{array}{l}\text { Kesesuaian } \\
\text { thd kondisi } \\
\text { geologis \& } \\
\text { hidrologis }\end{array}$ & Baik & Baik & Cukup \\
\hline $\begin{array}{l}\text { Kekakuan } \\
\text { menghadapi } \\
\text { gaya lateral }\end{array}$ & Cukup & Cukup & Cukup \\
\hline $\begin{array}{l}\text { Berdasarkan tabel penilaian pondasi di atas } \\
\text { maka pondasi yang dipilih untuk Bangunan }\end{array}$ \\
Utama adalah pondasi pondasi Foot Plate. \\
\hline
\end{tabular}

b. Superstructure

Kolom

Kolom diperlukan untuk menyalurkan beban ke pondasi. Menghindari bentuk kolom yang memiliki sudut tajam, juga meminimalkan bentuk-bentuk yang menyudut agar lebih memberikan kesan lues dan tidak kaku, maka pemilihan bentuk kolom bundar/ tabung.

Balok

Balok digunakan untuk mendukung beban di atasnya.

\section{Dinding}


Fleksibilitas dalam desain dinding sangat diperlukan maka konstruksi yang digunakan adalah konstruksi rangka di mana dinding tidak berfungsi sebagai pemikul beban. Beban dari atap disalurkan ke pondasi lewat kolom. Bahan yang digunakan sebagai dinding bercirikan hightech yaitu bahanbahan fabrikasi, batako, kaca, alumunium.

c. Upper structure

1) Tujuan: menentukan Upperstructure yang sesuai dengan bentuk showroom.

2) Dasar pertimbangan: bentuk dasar showroom, luas area yang ditutupi oleh atap (bentang lebar), penggunaan struktur yang tepat, salah satu bagian yang dapat dijadikan ekspose bangunan.

3) Proses analisis

Upper struktur bangunan utama menggunakan struktur space frame. struktur penutup bangunan yang berbentuk streamline dengan bentang lebar, struktur penyangga plat lantai dan struktur pondasi. Struktur penutup bangunan bangunan utama showroom ini memiliki bentuk streamline. Untuk mendapatkan bentuk streamline dan memiliki struktur yang stabil maka digunakan struktur kombinasi spaceframe, cable dan folded. Plat lantai yang digunakan pada bangunan utama showroom adalah plat lantai beton K-400 sehingga memiliki ketebalan yang relatif tipis dan sangat rigid. Untuk penutup atap plat baja, transparan dan metal roof adalah material untuk atap showroom mobil ini.

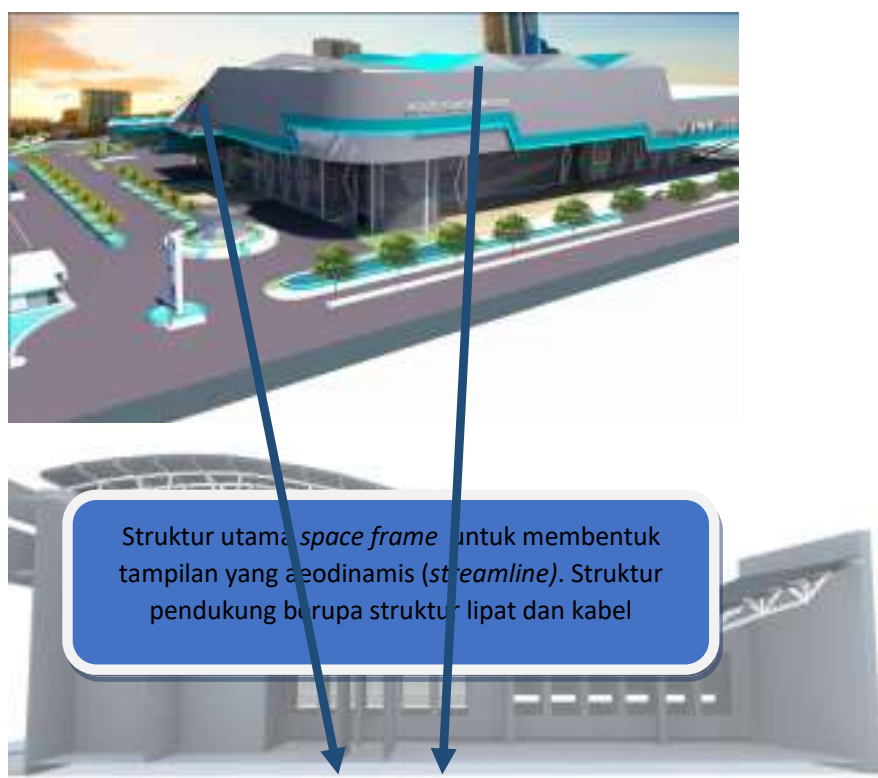

Gambar 3. Analisa tampilan Upperstructure showroom

\section{KESIMPULAN (KONSEP DESAIN)}

Konsep rancangan showroom mengacu pada pendekatan Arsitektur Hightech dan mewakili wadah showroom sebagai wadah pemenuhan kebutuhan pemilik kendaraan roda empat. Serta dirancang untuk menjadi aspek interest bangunan sebagai bangunan komersial. Dari hasil analisa serta hasil korelasi dari beberapa data di atas, maka diperoleh hasil berupa rancangan Showroom Mobil di Surakarta sebagai berikut. Nama Stadion : Hightech Car Showroom

\section{Lokasi : Jl. Slamet Riyadi}

Surakarta

Luas Lahan : $41.975 \mathrm{~m}^{2}$

Luas Bangunan : $31.636 \mathrm{~m}^{2}$

Daya Tampung : 500 kendaraan

Kegiatan : Fasilitas otomotif roda empat 


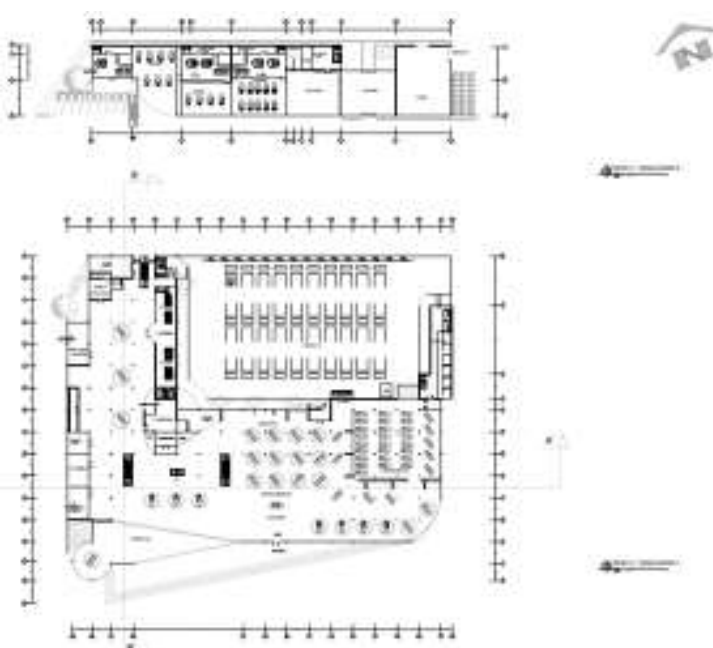

Gambar 4. Denah Lt.1 Showroom

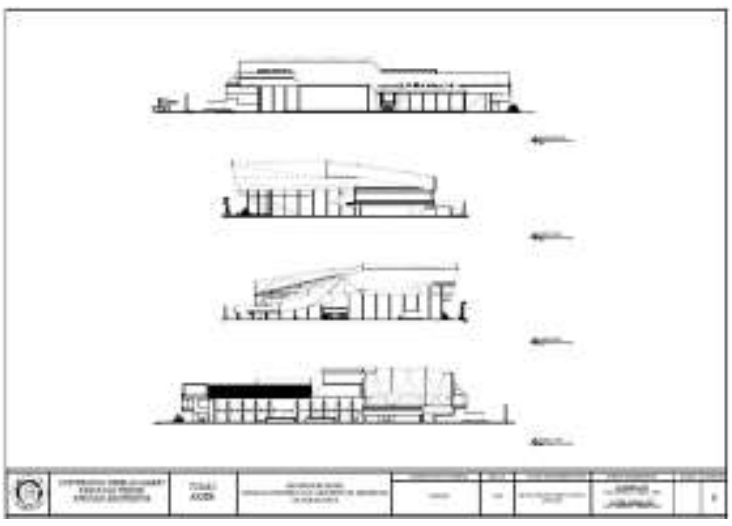

Gambar 5 . Tampak Showroom

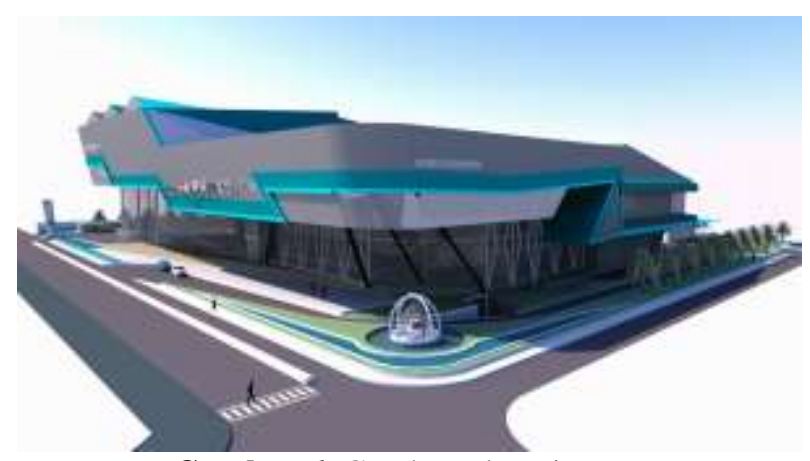

Gambar 6. Gambar Eksterior

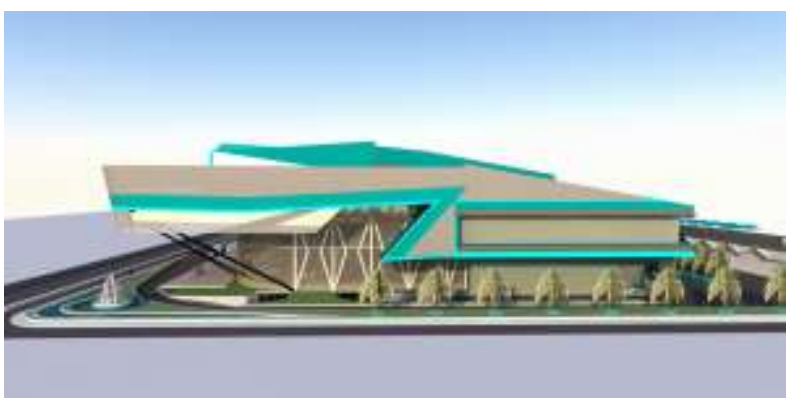

Gambar 6. Gambar Eksterior

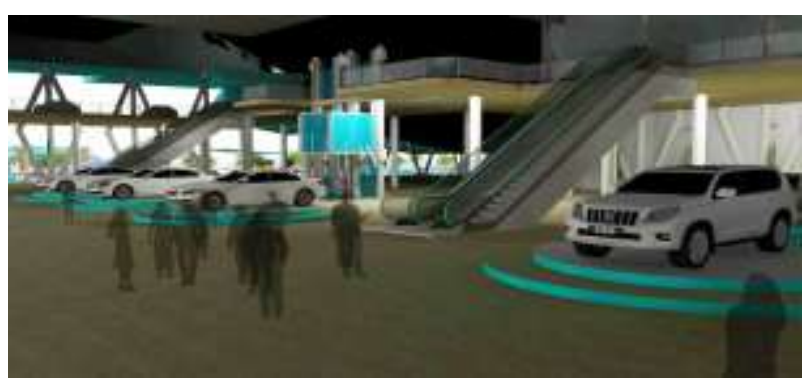

Gambar 7. Gambar Interior

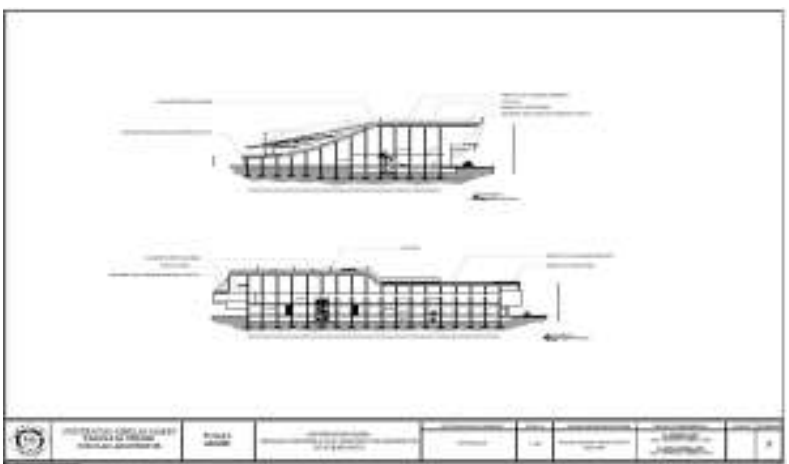

Gambar 8. Potongan showroom

\section{REFERENSI}

Gilbert Mc Devinn, Showroom Definition, Edisi 154, Penerbit Kompas Gramedia Building unit 2 Lt 1, Jakarta, 2009

(Jenck C) Enginering Hightech Architecture and interior. Thames and Huston. Great britain 